\title{
ANAESTHESIA FOR DAY-CARE SURGERY: A SYMPOSIUM (IV)*
}

\author{
ANAESTHESIA FOR PAEDIATRIC OUT-PATIENTS
}

\author{
DAVID J. STEWARD
}

\begin{abstract}
Out-patient surgery for infants and children offers the advantages of minimal emotional upset. less risk of infection, and fiscal economy. Many different operations can be done in the out-patient department and most children can be accepted for general anaesthesia for these operations. Preparation of the child is similar to that required for in-patient surgery. Premedication is unnecessary and contraindicated. A variety of techniques may be selected for induction of anaesthesia without unduly prolonging recovery. General inhalation anaesthesia with halothane is preferred for maintenance. Careful tracheal intubation should be utilized whenever indicated. Regional analgesia has many advantages over narcotic analgesics in the treatment of post-operative pain. A follow-up service should be provided.
\end{abstract}

Minor surgical procedures for infants and children have been done under general anaesthesia in the out-patient department for many years.' Recently, however, in North America and Europe, there has been a greatly increased interest in out-patient surgery for children, and during the past ten years the number of operations done on an out-patient or day basis has increased dramatically. Further expansion of paediatric out-patient surgery is inevitable and it has been suggested that more than 50 per cent of all children who have operations are suitable for treatment as out-patients. ${ }^{2}$

Surgery as an out-patient has several advantages for the child. Separation from family and home are minimized and consequently the emotional trauma of the hospital experience is reduced or avoided. ${ }^{3}$ This is of particular benefit in preschool-age children. The risk of hospitalacquired infection is also very much reduced. It is recognized that as many as 17 per cent of paediatric patients admitted for surgical procedures may acquire respiratory or enteric infections while in hospital. ${ }^{4}$ The incidence of such infections can be reduced by up to 70 per cent when the operations are done on an out-patient basis. ${ }^{5} \mathrm{~Pa}$ rents usually participate enthusiastically in the

* Presented as a Panel at the Annual Meeting, Canadian Anaesthetists' Society, June 1979.

David J. Steward, M.B., F.R.C.P.(C), Professor of Anaesthesia, University of Toronto. Anaesthetist-inChief, The Hospital for Sick Children, Toronto, Ontario, Canada.

Reprint Address: Department of Anaesthesia, Room 2303, The Hospital for Sick Children, 555 University Avenue, Toronto, Ontario, M5G 1 X8.

Canad. Anaesth. Soc. J., vol. 27, no. 4, July 1980 preparation and the postoperative care of their child and prefer this to having the child admitted to hospital. Thus the experience may be of value to the whole family unit. Finally, the total cost of treatment is much reduced when operations are done as an out-patient in the department, a benefit to all those who bear the cost of health care programs. ${ }^{6}$

\section{Selecrion of patients}

The initial selection of patients for surgery in the out-patient unit will usually be made by the surgeon. Therefore it is essential that the anaesthetist and surgeon have previously reached an agreement on which patients and which operations are suitable for the out-patient department.

The age and physical status of the patient must be considered. Though some anaesthetists prefer not to anaesthetize infants under six months of age as out-patients, many will accept younger patients. At our hospital patients of any age are accepted and, indeed, it is considered that the new-born infant may benefit as much as any child if hospitalization and consequent separation from the mother can be avoided.

Opinions on the physical status requirement for out-patient general anaesthesia also vary. A few anaesthetists would limit out-patient general anaesthesia to children of physical status I of the American Society of Anesthesiologists (A.S.A.). Many others will accept children who suffer from a chronic disease, provided that the disease is under good control and, most important, provided that the operation on an out-patient basis does not introduce any increase in the over-all 
TABLE I

Procedures Suitable For the Out-Patient

\begin{tabular}{l}
\hline Otology \\
Myringotomy (with insertion of ventilating tubes) \\
Removal of Foreign Body \\
General surgery \\
Herniotomy \\
Orchidopexy \\
Sigmoidoscopy \\
Anal dilation \\
Frenulectomy \\
Plastic surgery \\
Octoplasty \\
Superficial and integumentary lesions \\
Ophthalmology \\
Lacrimal duct probing \\
Chalazion \\
Examination under anaesthesia \\
Strabismus or ptosis correction \\
Contact lens fitting \\
Urology \\
Cystoscopy \\
Circumcision \\
Meatotomy \\
Dental surgery \\
Conservation \\
Extraction \\
Oral surgery \\
\end{tabular}

risk of the procedure. Many children with chronic diseases will, in fact, benefit substantially from having operations done as out-patients. Hospital-acquired infections may pose a special risk to these children and operation as an outpatient also largely avoids the additional emotional trauma of repeated hospitalization.

The paediatric surgical procedures which are commonly considered suitable for the out-patient department are listed in Table I. Other operations which result in minimal physiological disturbance and require no specialized postoperative care may also be considered suitable for out-patients. As can be seen, this will include a considerable portion of the spectrum of paediatric surgery.

\section{Preoperative preparation}

The preparation of the child for out-patient surgery will, of necessity, generally be the responsibility of the parents. This being so, it is quite essential that they be provided with clear concise instructions. These should detail the requirement for preoperative fasting and, in addition, provide advice on how to prepare the child psychologically for the procedure. The Parent Information Form presently in use at The Hos-

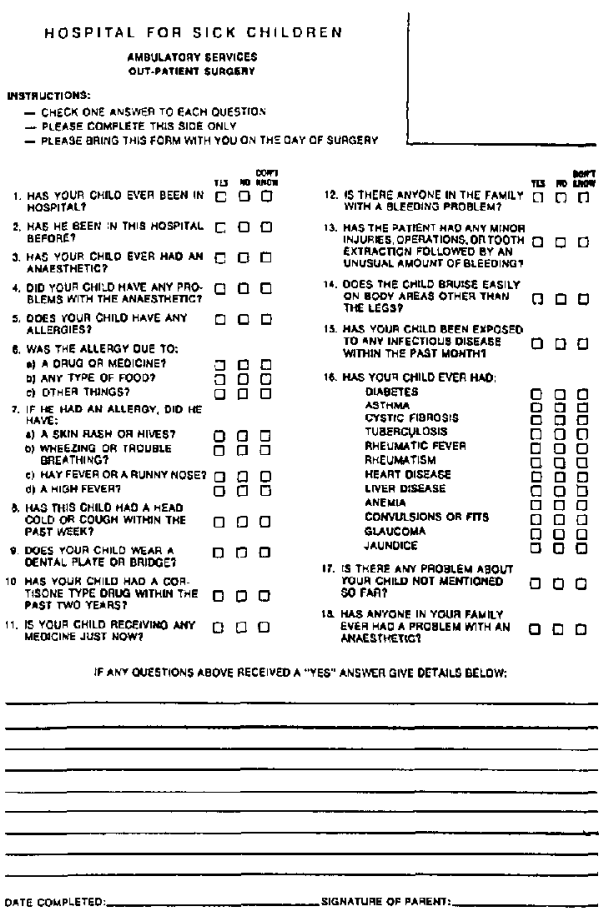

Figure 1 Medical history questionnaire to be com. pleted by parents before coming to the Out-Patients Surgical Department at The Hospital for Sick Children. Toronto.

pital for Sick Children, Toronto,* gives detailed instructions, including preoperative food and fuid restrictions.

Preoperative assessment should consist of a detailed history, physical examination, and routine laboratory studies ( $\mathrm{Hb}$ estimation, urinalysis, and sickle cell test if indicated). It is helpful to use a medical history questionnaire form which parents can complete before coming to the out-patient surgical department (see Figure) from which the anaesthetist can rapidly complete the history.

\section{Premedication}

Narcotics, hypnotics, and other sedative drugs are usually unnecessary and should.not be given, as they may contribute to morbidity and delay postoperative recovery. ${ }^{7}$ Indeed, most children who are scheduled for out-patient surgery will not require any pre-operative sedation, provided a kind and reassuring approach is used by the medical, nursing, and ancillary staff. Very apprehensive children and especially those having

* This may be obtained on request from the author. 
repeated procedures may benefit from premedication, but this must be given by the mother before bringing the child to the hospital. Diazepam suspension in a dose up to $0.5 \mathrm{mg} \cdot \mathrm{kg}^{-1}$ given orally may be effective. If this is ordered it should be made quite clear that this is the only oral intake allowed. Drugs which have to be administered by intramuscular injection should be avoided. Intramuscular injections are painful and are not a good way to calm and reassure a child.

Though there is seldom any need for sedative premedication, an anti-cholinergic drug should be given to all patients, preferably intravenously at the time of induction of anaesthesia. Atropine $0.02 \mathrm{mg} \cdot \mathrm{kg}^{-1}$ to a maximum of $0.6 \mathrm{mg}$ is preferred and may be mixed with the induction dose of thiopentone. Atropine is preferred to either hyoscine or glycopyrrolate as it provides an adequate block of the cardiac vagus with less drying of secretions in the mouth and respiratory tract. If rectal methohexitone is used for induction (see below), the usual dose of atropine may be added to this and given rectally.

\section{Anaesthetic techniques}

Anaesthetic techniques chosen for induction and maintenance of anaesthesia in the out-patient should provide the safest and most pleasant induction possible, good operating conditions for the surgeon, rapid post-anaesthetic recovery to street-fitness, and minimal postoperative morbidity.

The need for rapid recovery is obvious if the patient is to be fit for discharge within an hour of the end of the operation. Equal attention should be directed to minimizing the minor complications which may follow general anaesthesia. Loss of appetite, for example, is potentially more serious in the out-patient when the mother alone will be responsible for the postoperative care.

\section{Methods for induction of anaesthesia}

Induction of anaesthesia in children is recognized as a potentially upsetting experience which may cause lasting psychological disturbance. For the out-patient an additional consideration is the effect that induction agents may have on the duration of post-anaesthetic recovery and the incidence of minor morbidity at home after the operation.

For older children (over 5 years) we prefer intravenous induction of anaesthesia using a 2.5 per cent solution of thiopentone (dose 5 $\mathrm{mg} \cdot \mathbf{k g}^{-1}$ ). Intravenous induction, if skillfully and painlessly done, has been shown to cause less psychological upset than inhalation induction methods. ${ }^{8}$ Intravenous thiopentone in a dose of 5 $\mathrm{mg} \cdot \mathrm{kg}^{-1}$ does not delay recovery significantly in the post-anaesthetic room (P.A.R.) and has been shown not to delay the recovery of the patient to a normal status at home. ${ }^{1}$

If an older child requests an inhalation induction he should be allowed to hold the mask to his face while anaesthesia is commenced with nitrous oxide and halothane. By holding on to the mask the child gains a measure of participation in the process and is more likely to co-operate well.

Very young infants (under 6 months) may be taken to the operating room and are not upset by a skillfully administered inhalation induction of anaesthesia using nitrous oxide and halothane. In this age group the use of an inhalation induction does result in a slightly more rapid postoperative recovery following a short operation $(<30 \mathrm{mi}-$ nutes) than if a barbiturate induction agent is used. This is important for infants, who should be fully awake before being left to the care of the recovery room staff.

Children over six months of age are upset when taken from their parents to the operating room. They are old enough to appreciate a threatening situation and until four or five years of age are too young to be reassured or to understand an explanation of what is happening. For children in this age range a 'non-invasive' technique of induction of anaesthesia is ideal, and rectal methohexitone has been used with success. ${ }^{9}$ The drug may be administered in a suitably equipped area adjacent to the operating room with the parents present. The anaesthetist should be in attendance throughout and must ensure that resuscitation equipment is immediately available. Recovery following the use of rectal methohexitone for induction is slightly delayed when compared to that following intravenous thiopentone. However. after the first $\mathbf{3 0}$ minutes in the P.A.R. there is no detectable difference between the state of recovery of patients who had either method of induction. Recovery to a normal status at home is not delayed by the use of rectal methohexitone. ${ }^{9}$

\section{Maintenance of anaesthesia}

Simple anaesthetic routines are preferred. Inhalation agents are considered preferable to intravenous drugs because recovery is more rapid and complete. Halothane has proved to be a very useful agent for the paediatric out-patient. Induction is smooth and swift, the level of anaesthesia is easily controlled, recovery is fast and postoperative complications are minimal. 
Enflurane initially appeared to have physical properties which would make it ideal for use in out-patients. In actual trials, however, enflurane has shown no advantage over halothane for the paediatric out-patient. ${ }^{9,10}$

Mask anaesthesia with spontaneous respiration is suitable for many out-patient procedures. The Jackson-Rees modification of the T-piece is the preferred anaesthetic circuit; it is lightweight, convenient, and readily adapted to gas scavenging equipment. Fresh gas flows during spontaneous respiration must be adequate to prevent rebreathing.

Whenever indicated, tracheal intubation should be employed during anaesthesia. However, for the out-patient, extreme care should be exercised to be gentle at laryngoscopy and to choose an optimal size of tube. Post-intubation stridor is most commonly caused by traumatic intubation or by the use of a tube of excessive diameter. ${ }^{12}$ A leak of anaesthetic gases around the tube on positive pressure inflation of the lungs must always be demonstrated to confirm that the tube is not too large. If succinylcholine is used to facilitate intubation, this drug should be preceded by d-tubocurarine $0.05 \mathrm{mg} \cdot \mathrm{kg}^{-1}$ intravenously to prevent postoperative muscle pains. Succinylcholine-induced muscle pains are less common in small children, but do occur in some patients who are ambulatory following minor operations. If d-tubocurarine is administered the dose of succinylcholine should be increased by 75 per cent to ensure adequate relaxation for intubation.

\section{Postoperative care}

Following operation the patient must be cared for in an adequately staffed and equipped postanaesthetic room. Until consciousness returns all patients should have oxygen and must be closely observed by the nursing staff. The initial recovery from anaesthesia should be documented using a post-anaesthesia recovery scoring system. ${ }^{13}$ Once the child recovers consciousness he should be encouraged to sit out of bed and to take sips of clear fluid. As soon as small infants are awake their parents may be called to the P.A.R. to nurse them.

\section{Postoperative pain and its treatment}

Small infants under three months of age generally do not require analgesic drugs, but will settle quite happily if nursed. Older children will usually require some form of analgesia following all but the most minor superficial operations. Narcotic analgesics may be administered, but these drugs delay recovery to a normal status and will also increase the incidence of postoperative nausea and vomiting. Salicylates may be effective against less severe pain but may increase the risk of postoperative bleeding, so that acetaminophen (Tylenol)* is usually preferred.

Regional analgesia, when possible, is an ideal technique for providing postoperative pain relief for the out-patient. Sensory nerve block persists for several hours if bupivacaine is used. The patient will have a more rapid return to normal activity than if narcotics are administered, and postoperative nausea and vomiting is reduced. If the regional block is done immediately after induction of general anaesthesia and before the operation starts, the requirement for general anaesthetic agents is reduced, with a resulting acceleration of post-anaesthesia recovery and a decrease in minor morbidity. ${ }^{14}$ Regional nerve block can provide analgesia over many parts of the body and is readily applicable to operations in the inguinal regional (ilio-hypogastric and ilioinguinal nerve block) and the perineal region (caudal or penile block).

\section{Criteria for discharge}

Most infants and children may be safely discharged home in the care of their parents after one hour in the P.A.R. Patients who are not fully recovered or who are dizzy, nauseated or who have other complications should be retained for a further period. Following tracheal intubation a patient may be safely discharged if no complications have presented within one and a half hours of the operation.

Before being discharged every patient should be signed out by an anaesthetist who should carefully check the postoperative course. Before being considered for discharge, the child who is old enough to walk should have a steady gait. All patients should be offered fluids before discharge, and be able to take these without nausea or vomiting.

More specific tests for assessing recovery from anaesthesia have been described but are generally not easily applicable to the paediatric outpatient.

\section{Recovery at home}

Parents should be advised to proceed directly home with their child. For infants and small children it is preferable to have a second person in

${ }^{*}$ Tylenol ${ }^{\oplus}$ McNeil Laboratories (Canada) LId., Stouffuille, Ontario. 
addition to the driver, if the journey is to be made by private car.

Once home the child may be allowed as much activity as he wishes. Fluid intake should be encouraged and a normal diet gradually reintroduced depending upon the appetite of the child. If further analgesics are required acetaminophen (Tylenol) is recommended.

The parents should be provided with a telephone number to call for advice should any problem arise. Many institutions also place a routine telephone call after 24 hours to check on the progress of the patient and to document this.

\section{REFERENCES}

1. STEward $;$ D.J. Out-patient paediatric anaesthesia. Anaesthesiology 43: 268-276 (1975).

2. ShaH, C.P. Personal communication (1979).

3. STEWARD, D.J. Experience with an out-patient anaesthesia service for children. Anaesth. Analg. (Cleve) 52: 877-880 (1973).

4. IZANT, R. Nosocomial infections in a children's hospital. 27th Ross Paediatric Research Conference (1958).

5. Otherson, H.B. \& Clatworthy, H.W. Outpatient herniorrhaphy for infants. Am. J. Dis. Child. 1/6: 78-80 (1968).
6. Shaн, C.P. Day care surgery in Canada: Evolution, policy and experience of provinces. Canad. Anaesth. Soc. J. (this issue).

7. Booker, P.D. \& Chapman, D.H. Premedication in children undergoing day care surgery. Brit. J. Anaesth. 5/: 1083-1087 (1979).

8. KAY, B. Out-patient anaesthesia, especially for children. Acta Anaesth. Scand. Suppl. 25; 421-425 (1966).

9. Goresky, G.V. \& Stewaro. D.J. Rectal methohexital for induction of anaesthesia in children. Canad. Anaesth. Soc. J. 26: 213-215 (1979).

10. Horne, J.A. \& Ahlgren, E.W. Halothane. enflurane, and is oflurane for out-patient surgery: a paediatric case series. Abstracts of the Annual Meeting of the American Society of Anacsthesiologists, Park Ridge, Ill. (1973).

11. Steward, D.J. A trial of enflurane for paediatric out-patient anaesthesia. Canad. Anaesth. Soc. J. 24: 603-608 (1977).

12. KoKA, B.V., JEON, I.S., ANDRE, J.M., MACKaY, I. \& SMIth, R.M. Post intubation croup in children. Anaesth. Analg. (Cleve) 56: 501-505 (1977).

13. STEWARD, D.J. A simplified post-anaesthetic recovery scoring system. Canad. Anaesth. Soc. J. 22: $111-113(1975)$

14. Shandling, B. \& Steward, D.J. Regional analgesia for post-operative pain in paediatric outpatient surgery. J. Paed. Surg. (in press).

\section{RÉSUMÉ}

La chirurgie ambulatoire offre des avantages importants tant pour le nourrisson et pour l'enfant: le bouleversement émotionnel est considérablement réduit, il y a moins de risques infectieux et une économie financière peut être réalisée. Plusieurs types d'interventions peuvent s'effectuer en chirurgie ambulatoire et la plupart des enfants sont acceptables pour ces interventions sous anesthésie générale. Une prémédication n'est ordinairement pas nécessaire et peut même faire l'objet d'une contre-indication. Plusieurs techniques sont disponibles pour l'induction de l'anesthésie sans risque de prolongation exagérée de la période de récupération à la salle de réveil ou à la maison. On préfere l'halothane pour le maintien de l'anesthésie et on ne devrait intuber la trachée que lorqu'il y a indication. Lorsqu'on a besoin d'analgésie à la période post-opératoire, l'anesthésie régionale présente des avantages sur l'administration de narcotiques. Un service de surveillance post-opératoire doit être disponible. 